Journal of Empowerment Community

Vol. 1 No. 2, September 2019

\title{
PEMBELAJARAN KARAKTER MELALUI PELAKSANAAN IDUL ADHA PADA SISWA SMA
}

\author{
Nana Suyana ${ }^{1^{*}}$, Lusiana Wulansari ${ }^{2}$ \\ ${ }^{1}$ Program Studi Teknik Industri, Fakultas Teknik dan IImu Komputer, Universitas Indraprasta PGRI Jakarta \\ ${ }^{21}$ Program Studi Bimbingan Konseling, Fakultas IImu Pendidikan dan Pengetahuan Sosial Universitas \\ Indraprasta PGRI \\ * Penulis Korespodensi : lusianawulansari58@gmail.com
}

\begin{abstract}
Abstrak (12pt Bold)
Pembelajaraan karakter sangat diperlukan, agar siswa dapat dibekali lebih dini tentang tantangan zaman yang cepat berubah. Perubahan tersebut dapat diimbangi, dengan pendidikan karakter yang mumpuni, sehingga para siswa mempunyai jiwa dan hati yang teduh, saling tepo seliro, saling menghormati dan kasih sayang pada sesamanya. Pelaksanaan kegiatan pengabdian masyarakat dilaksanakan pada bulan Juli dan Agustus 2019. Metode yang digunakan adalah ceramah dan pelaksanaan kegiatan secara langsung serta evaluasi kegiatan. Hasil kegiatan pembelajaran akhlakul karimah melalui kegiatan Idul Adha, terlihat siswa lebih toleran dan menghormati sesama siswa serta dapat menghormat kepada para guru dan orang tua dirumah. Selain itu mereka lebih memahami secara teori dan praktek nilai- nilai pengorbanan pada perayaan Idul Adha.
\end{abstract}

Kata Kunci : Pembelajaran, Karakter,Idul Adha.

\begin{abstract}
Character learning is needed, so students can be equipped early about the challenges of a rapidly changing era. These changes can be balanced, with qualified character education, so that students have a shady heart and heart, tepo seliro each other, mutual respect and affection for each other. The implementation of community service activities was carried out in July and August 2019. The method used was a lecture and direct implementation of activities and evaluation of activities. The results of the morality learning activities through the activities of Eid al-Adha, students look more tolerant and respectful of fellow students and can respect teachers and parents at home. In addition they better understand in theory and practice of the values of sacrifice at the celebration of Eid alAdha.
\end{abstract}

Keywords : Learning,character ,Idul Adha

\section{Pendahuluan}

Hari Raya Idhul Adha merupakan hari besar umat Islam di seluruh dunia dimana pada hari tersebut didalamnya terdapat suatu kegiatan yakni penyembelihan hewan ternak (Kurban) dengan tujuan mendapatkan ridho Allah Swt. Sedangkan penyembelihan hewan ternak (kurban) secara etimologi berasal dari kata bahasa Arab, yakni Qaraba, Yaqrabu, Quban wa qurbanan wa qirbanan yang meliki arti dekat. Jadi, kurban berarti mendekatkan diri kepada Allah SWT dengan mengerjakan sebagian perintah-Nya. Kurban dalam 
pengertian kita sehari-hari sebenarnya diambil dari kata udhhiyah yakni bentuk jama' dari kata "dhahiyyah" yaitu sembelihan pada waktu dhuha tanggal 10 sampai dengan 13 Dzulhijjah. Dari sinilah muncul istilah "Idul Adha".

Dengan demikian yang dimaksud dengan kurban atau udhhiyah adalah penyembelihan hewan dengan tujuan beribadah kepada Allah pada hari raya Idul Adha dan tiga hari Tasyriq, yaitu tanggal 11, 12 dan 13 Dzulhijjah. Dalam sejarahnya, kurban menurut firman Allah SWT dalam Q.S. Al Maidah : 27 "Ceriterakanlah kepada mereka kisah kedua putra Adam (Habil dan Kabil) menurut yang sebenarnya, ketika keduanya mempersembahkan kurban, maka diterima dari salah seorang dari mereka berdua (Habil) dan tidak diterima dari yang lain (Kabil). la berkata (Kabil): "Aku pasti membunuhmu!" Berkata Habil: "Sesungguhnya Allah hanya menerima (korban) dari orang-orang yang bertakwa". (Q.S. Al Maidah [5]: 27).

Dalam kandungan ayat ini bahwa dalam berkurban dibutuhkan keikhlasan dan persembahan kepada Allah dan ketaqwaan kita kepada-Nya. Seperti, dikisahkan pada era nabi Adam a.s., kurban sudah diperkenalkan. Beliau mendapat perintah dari Allah agar kedua anaknya melakukan kurban. Caranya dengan "mempersembahkan" hasil bumi dan hewan ternak. Kedua anaknya, Qobil dan Habil segera memenuhi perintah tersebut. Habil yang peternak, dengan sepenuh hati berkurban untuk mencari ridha Allah dengan menyiapkan hewan terbaiknya untuk kurban. Sebaliknya, Qabil, yang petani, melaksanakan perintah tersebut dengan tidak ikhlas karena Allah, ia merasa terpaksa. la berkurban dengan buah-buahan yang busuk yang ia sendiri tidak menyukainya. Kurban Habil diterima oleh Allah sedangkan kurban Qabil ditolak. Kisah tersebut dapat dijadikan suri tauladan yang baik bagi kita semua.

Adapun makna kurban adalah sebagai berikut :

1. Merupakan pencerah jiwa karena dengan berkurban berarti jiwa kita terhubung dengan ketaqwaan kepada Allah SWT;2. dapat memupuk keikhlasan, kejujuran dan kesabaran yang membimbing kita mencintai Allah dan akhirnya juga mencintai makhluk ciptaanNya.3, mempererat tali persaudaraan kepada sesama manusia serta sikap solidaritas yang tinggi; dan, 4. memperkuat keteguhan hati dan jiwa dalam diri kita.

Semua makna kurban di atas harus dicermati dan diperhatikan baik-baik karena sungguh berkurban berarti pendekatan kita kepada Allah SWT. Sikap iman dan taqwa juga meliputi itu semua. Kesadaran dalam jiwa yang menumbuhkan sikap iman dan taqwa dalam diri kita dengan makna-makna tersebut. Sumbangan hewan yang akan diserahkan merupakan hewan yang terbaik. ( Assofwa , 2011).

Berat sekali ujian keimanan pada era global seperti sekarang ini. Idealisme sulit ditemukan dan pragmatisme menjadi fenomena sehari-hari. Merosotnya nilai-nilai ideal tidak saja dalam dunia bisnis tetapi juga dalam hidup bermasyarakat, berbangsa dan bernegara. Kalau dalam masyarakat, orang yang dipandang dan dihormati adalah mereka yang memiliki kekayaan berlebih, maka korupsi akan tumbuh subur. Untuk itu sebagai umat islam yang baik ,selalu bertawakal , tawakal adalah membebaskan hati dari ketergantungan 
kepada selain Allah SWT dan menyerahkan segala keputusan hanya kepada-Nya ( MA Bunga dkk, 2019)

Selanjutnya, para umat islam yang melaksanakan idul adha, merupakan praktek dari saling mengasihi dan menyayangi sesama umat. Pada pelaksanaan idul adha di SMAN Terbuka 14 Bekasi, berusaha untuk dapat menjadi bagian pembelajaran karakter siswa SMA. Penanaman karakter yang baik sejak dibangku sekolah, merupakan strategi pembelajaran yang cocok digunakan demi pencapaian akhlakul karimah para siswa . Momen kegiatan yang dilakukan pada idul kurban tahun 2019, digunakan untuk menambah nilai karakter pada siswa SMA.

\section{Metode}

Metode pelaksanaan menggunakan metode ceramah dan pelaksanaan kegiatan secara praktek langsung serta evaluasi kegiatan. Dapat digambarkan tahapan diagram pelaksanaan sebagai berikut :

\begin{tabular}{|l|l|l|}
\hline $\begin{array}{l}\text { Penyuluhan } \\
\text { dan Persiapan } \\
\text { serta } \\
\text { pembekalan }\end{array}$ & $\begin{array}{l}\text { Pelaksanaan } \\
\text { Kegiatan : } \\
\text { 1. Dimesjid } \\
\text { 2. Wilayah } \\
\text { sekitar mesjid }\end{array}$ \\
\hline
\end{tabular}

Pada pelaksanaan kegiatan pengabdian masyarakat tim yang terdiri dari dua orang dosen dan dibantu oleh mahasiswa memberikan beberapa penjelasan dengan berceramah, menerangkan pentingnya berkurban untuk umat muslim, dan umat lain. Pelaksanaan ceramah dibagi menjadi 2 sesi. Sesi awal perkenalan dan menjawab beberapa pertanyaan tentang program tim pelaksanan pengabdian masyrakat. Pada sesi 2 , tim memberikan materi singkat tentang idul adha secara teori . Jumlah siswa yang ikut pada pelaksanaan kegiatan sebanak 37 siswa. Jumlah tersebut dibagi menjadi 5 kelompok. Kelompok pertama menghimpun dana kurban. . kelompok kedua menyiapkan alat alat pelaksanaan berkurba, kelompok 3 membantu komsumsi. Kelompok 4 membantu pembagian daging kurban. Kelompok 5 , membantu pelaksanaan penyembelihan kurban.

Pada metode pelaksanaan praktek langsung, siswa membantu pada kegiatan persiapan, penyembelihan, pembagian daging, dan kegiatan pembersihan alat - alat kerja , dan terakhir evaluasi kerja program.

Menguraikan cara yang digunakan untuk menyelesaikan masalah. Contoh metode : a) Pendidikan Masyarakat, misalnya penyuluhan yang bertujuan meningkatkan pemahaman serta kesadaran, b) Difusi Ipteks, misalnya kegiatan yang menghasilkan produk bagi kelompok sasaran, c) Pelatihan, misalnya kegiatan yang disertai dengan demonstrasi atau percontohan untuk menghasilkan keterampilan tertentu, d) Mediasi, misalnya kegiatan yang 
menunjukkan pelaksana Pengabdian masyarakat sebagai mediator dalam menyelesaikan masalah yang ada dalam masyarakat, e) Advokasi, misalnya kegiatan yang berupa pendampingan terhadap kelompok sasaran. Jelaskan juga karakteristik kelompok sasaran yang menjadi mitra kegiatan Pengabdian masyarakat.

\section{Hasil dan Pembahasan}

Metode pelaksanaan menggunakan metode ceramah dan pelaksanaan kegiatan secara praktek langsung serta evaluasi kegiatan. Pada pelaksanaan kegiatan pengabdian masyarakat tim yang terdiri dari dua orang dosen dan dibantu oleh mahasiswa memberikan beberapa penjelasan dengan berceramah, menerankan pentingnya berkurban untukumat muslim, dan umat lain. Pelaksanaan ceramah dibagi menjadi 2 sesi. Sesi awal perkenalan dan menjawab beberapa pertanyaan tentang program tim elaksanan pengabdian masyrakat. Pada sesi 2 , tim memberikan materi singkat tentang idul adha secara teori . Jumlah siswa yang ikut pada pelaksanaan kegiatan sebanyak 37 siswa. Jumlah tersebut dibagi menjadi 5 kelompok. Kelompok pertama menghimpun dana kurban. . kelompok kedua menyiapkan alat alat pelaksanaan berkurban, kelompok 3 membantu komsumsi. Kelompok 4 membantu pembagian daging kurban. Kelompok 5 , membantu pelaksanaan penyembelihan kurban.

Pada metode pelaksanaan praktek langsung, siswa membantu pada kegiatan persiapan, penyembelihan, pembagian daging, dan kegiatan pembersihan alat - alat kerja , dan terakhir evaluasi kerja program.

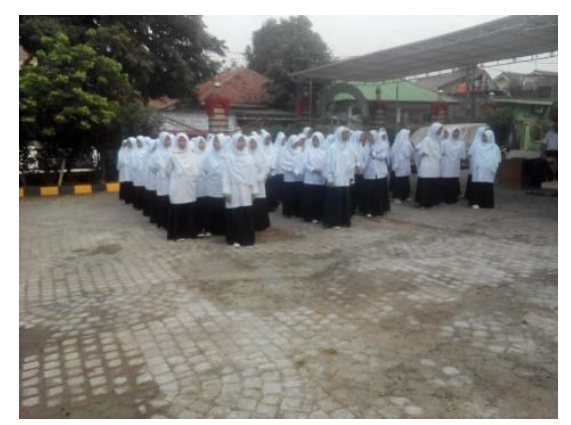

Gambar . 1. Siswi mendengar penjelasan Berkurban sebelum kegiatan.

Pada tahap penjelasan awal, siswa diberikan waktu untuk bertanya, dan menyimpulkan sendiri apa yang sudah didengar dari para pemateri. Siswa menuliskan kembali apa yang dimaksud dengan nilai - nilai berkurban. Tim pengadian masyarakat memberikan beberapa angket dan pertanyaan kepada para siswa. Siswa putri dan putra bertanya seutar nilai - nilai apa yang dapat diambil dari pelaksanaan idul korban. Para guru dan yayasan memberikan dukungan agar pelaksanaan dapat berjalan dengan baik.

Pada tahap selanjutnya, setelah melaksanakan beberapa pesiapan siswa, diberikan arahan cara 
memotong hewan kurban yang sesuai dengan Syariah agama. Seperti terlihat pada gambar 2. Siswa mulai membantu pelaksanaan penyembelihan hewan.

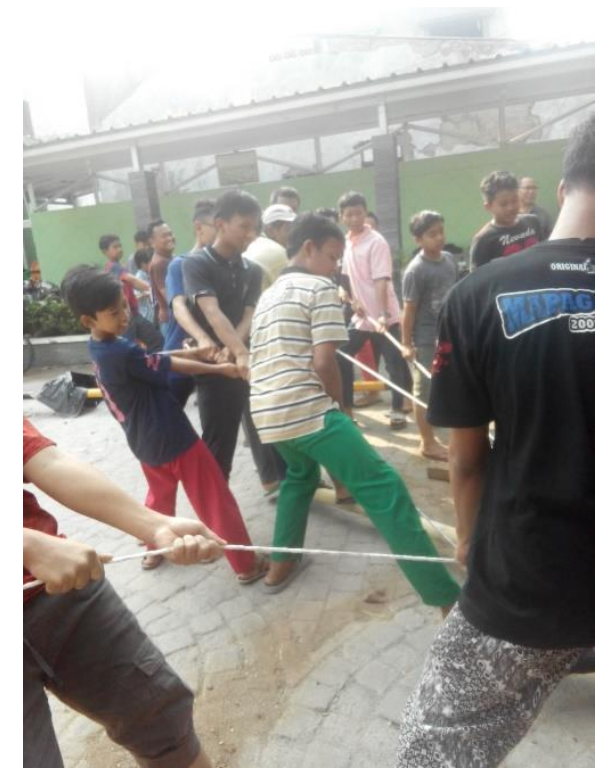

Gambar 2. Siswa melaksanaan penyembelihan

Setelah siswa membantu penyembelihan kurban ,mereka membersihkan lokasi, memotong daging dan mengemas daging. Sedangkan para siswi membantu memasak, untuk komsumsi.

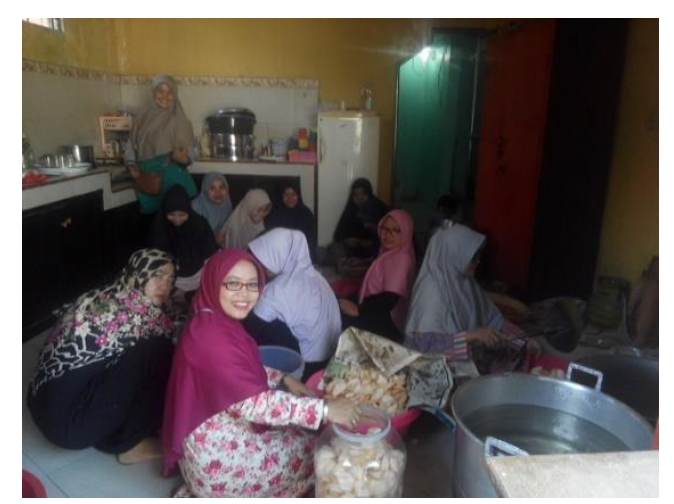

Gambar. 3. Para siswa dan guru membantu memasak komsumsi

Para masyarakat merasa terbantu dengan pelaksanaan pemotongan hewan di sekolah dan masjid. Dengan demikian pembelajaran karakter dapat di praktekkan langsung. Para tim berkeyakinan , bahwa dengan praktik langsung, siswa dapat mengetahui, dan merasakan nilai - nilai kebersamaan dan karakter yang terbangun menjadi nyata. Berikut tabel kegiatan yang dapat memberikan nilai nilai karakter beserta manfaatnya. 
Tabel 1. Tabel kegiatan dan nilai - nilai karakter

\begin{tabular}{ccc}
\hline No & Kegiatan & Nilai nilai karakter \\
\hline 1. & Belajar menyembelih hewan & Religius, keihklasan \\
2. & Membagikan daging kepada & Kesetiakawanan, \\
masyarakat & Menyumbang dana untuk & Kebersamaan, religius, kepedulian \\
& membeli hewan kurban & mengungari rasa kikir, berani \\
&
\end{tabular}

Sumber: Data Primer diolah (2019)

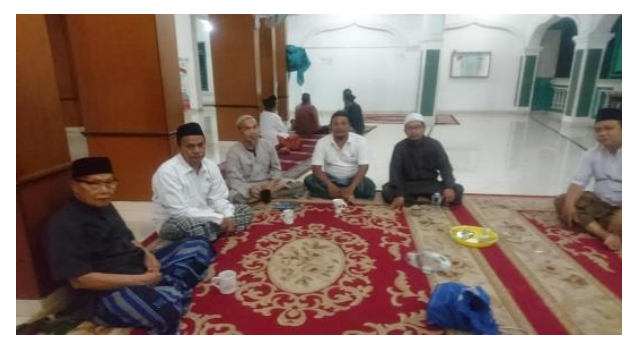

Gambar. 4. Para pengurus yayasan dan guru rapat evaluasi

\section{Simpulan}

Sesuai pembahasan diatas dapat disimpulkan bahwa :

1. Para siswa bersemangat untuk "fastabikul Khoiroh" . berlomba- lomba dalam kebaikan.

2. Pelaksanaan kegiatan, berlangsung dengan baik, sesuai dengan encana. Sehingga siswa dapat terlatih mencapai target yang sudah ditetapkan.

3. Siswa lebih toleran dan lebih toleran dan menghormati sesama siswa serta dapat menghormat kepada para guru dan orang tua dirumah. Selain itu mereka lebih memahami secara teori dan praktek nilai- nilai pengorbanan pada perayaan Idul Adha.

Adapun saran sebagai berikut :

1. Kegiatan dapat menjadi dasar pembelajaran nilai nilai karakter dan akhlakul karimah

2. Kegiatan dapat dilaksanakan tiap tahun, mengingat kegiatan ini sangat baik, bagi pembinaan karakter. 
Pada pelaksanaan program pengabdian masyarakat, tim melihat adanya tim work yang baik antara siswa dan guru serta yayasan. Perencanaan yang baik dan matang dapat dilaksanakan dengan tepat dan terarah. Siswa terlatih untuk dapat melaksanakan tugas tugas kemanusian seperti membagikan daging kepada masyarakat sehingga timbul rasa empathi kepada sesamanya. Para siswa juga memberikan sumbangan uang untuk dapat berkurban. Kegiatan ini dapat memberikan rasa keikhlasan dan kesederhanaan siswa, agar mau hidup sederhana. Mereka juga akan mendapat rasa keberanian, karena mau berkorban demi orang lain.

\section{Ucapan Terima Kasih}

Tim pengabdi masyarakat memberikan apresiasi kepada para pengurus yayasan yang dapat memberikan kesempatan kepada tim untuk memberikan pencerahan dan dukungan, agar dapat menjalankan program ini.

\section{Daftar Pustaka}

Alquran Nur Kariim, 2019, Kemenag: Qp Press

Assofwa , 2011. Keutamaan 10 Hari pertama Bulan Dzulhijjah dan Tuntunan Qurban. Assofwa Press: Jakarta

Alisha, N. (2017). Pengaruh promosi produk tabungan kurban terhadap minat berkurban di Nurul Fikri Zakat Center Kota Palangka Raya (Doctoral dissertation, IAIN Palangka Raya).

Ati, A. P., \& Widiyarto, S. (2019). Pembinaan Karakter Melalui Kegiatan Membaca Kritis Pada Siswa SMP Kota Bekasi. MATAPPA: Jurnal Pengabdian Kepada Masyarakat, 2(1), 39-42.

Burga, M. A., Marjuni, A., \& Rosdiana, R. (2019).

Nilai-nilai Tarbiyah Ibadah Kurban dan Relevansinya dengan Pembelajaran Pendidikan Formal. PALAPA, 7(2), 202-233.

Caniago, F., \& Ganesha, P. P. UPAYA TAKMIR MASJID AI-MUHAJIRIN DALAM MENINGKATKAN SEMANGAT BERKURBAN DI MASYARAKAT.

Hesti restianti 2014 Antara Akikah dan Kurban,Titian Ilmu : Jakarta

Lailah, L. (1999). Studi Tentang Qurban Dalam Agama Agama Samawi (Doctoral Dissertation, lain Sunan Ampel Surabaya). 
Hadist Bukori,

Hasbiyallah, H., DR., M.Ag., Dkk.2015. Hadis Tarbawi , Remaja rosdakarya:: Bandung

Widadi, A. (2016). Nilai Pendidikan Pada Syariat Kurban Kajian Tafsir Surat Al-Hajj Ayat 34 dan Surat Al-Kautsar Ayat 1-3 (Bachelor's thesis, jakarta: FITK UIN Syarif Hidayatullah Jakarta). 